\title{
Brief
}

\section{Complete excision of secondary chordae of the anterior mitral leaflet as an adjunct in surgical management of hypertrophic obstructive cardiomyopathy in pediatric patients}

\author{
A. Aharonyan, MD, H. G. Zohrabyan, MD, PhD, V. Manukyan, MD, PhD, and H. Hovaguimian, MD, FACS, \\ Yerevan, Armenia
}

From the Cardiac Surgery Department, Nork Marash Medical Center, Yerevan, Armenia.

Received for publication Feb 14, 2001; accepted for publication March 2, 2001

Address for reprints: A. Aharonyan, MD Cardiac Surgery Department, Nork Marash Medical Center, 13 Armenakyan St, Nork, Yerevan, 375047, Republic of Armenia.

J Thorac Cardiovasc Surg 2001;122:815-6

Copyright (C) 2001 by The American Association for Thoracic Surgery

$0022-5223 / 2001 \$ 35.00+0 \quad \mathbf{1 2 / 5 4 / 1 1 5 6 9 3}$

doi:10.1067/mtc.2001.115693
$\mathrm{T}$ here has been very little experience in surgical management of hypertrophic obstructive cardiomyopathy (HOCM) in the pediatric age group. However, the surgical techniques used are generally the same as in adults. Septal myectomy remains the most popular and the key component of most of the techniques used. ${ }^{1}$ Although the mitral valve (MV) replacement suggested by Cooley and colleagues ${ }^{2}$ would be an undesirable method in the pediatric age group, other techniques complementing septal myectomy, such as radical debridement and repositioning of the papillary muscles, can be useful. ${ }^{3}$ In this article we present 3 cases of HOCM in which, in addition to performing extensive septal myectomy, we also performed resection of all of the secondary chordae of the anterior mitral leaflet and repositioned one or both papillary muscles posteriorly. The relevant clinical data of the patients are summarized in Table 1.

\section{Surgical Technique}

Preoperative cardiopulmonary bypass was instituted by means of aortic and bicaval cannulation. The patients were cooled to $28^{\circ} \mathrm{C}$. The aorta was clamped, and cold hyperkalemic cardioplegic solution was used for myocardial protection and repeated every 25 minutes. Aortotomy was performed, and left atriotomy was performed parallel to the interatrial groove.

The left ventricular outflow tract (LVOT) was inspected through the aortic valve, with special attention to the subvalvular mitral apparatus. The MV was moved into the LVOT, simulating systolic anterior motion (SAM), and an attempt was made to identify whether one or both mitral commissures were involved in the SAM and subaortic obstruction. We found that patient 1 had both commissural ends involved, whereas patients 2 and 3 had only the anterolateral commissural end involved in the SAM. This identification was made by the presence of fibrotic jet lesions on the mitral leaflet edges and the chordal apparatus on each commissural end of the valve. The MV was inspected through the left atrium, and a black silk was passed behind all of the primary chordal groups of the anterior mitral leaflet to identify and protect them, while the secondary chordae were being resected from the aortic side. All of the secondary chordae of the anterior mitral leaflet (including normal-looking chordae) were excised. An extensive septal myectomy was performed that went beyond the bases of both papillary muscles. Repositioning of both papillary muscles was done in patient 1 , and only the anterolateral muscle was repositioned in patients 2 and 3 . The repositioning was done by suturing the papillary muscles to the posterior left ventricular wall midway between its base and its tip. The MV was confirmed to be competent by injecting cold solution under pressure. The aortotomy and the left atriotomy were closed; the patients were rewarmed and were weaned from cardiopulmonary bypass without difficulty. The outcomes of the procedure are summarized in Table 1.

At follow-up, patient 1 was asymptomatic. His echocardiogram shows normal left ventricle size and no LVOT gradient with absence of SAM. Patient 2 was lost to follow-up, and patient 3 had a short postoperative course with no changes.

\section{Discussion}

Idiopathic HOCM is a condition of unknown cause characterized by septal hypertrophy, a small LV cavity, increased systolic function, and impaired diastolic function with different 

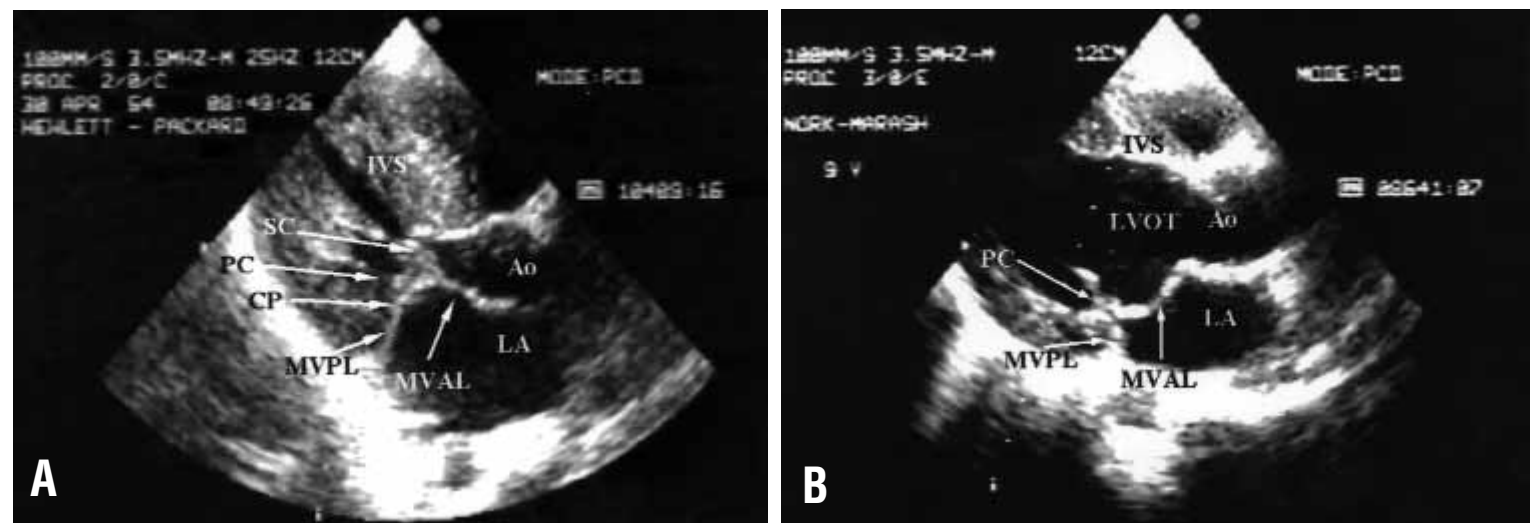

Figure 1. A, Preoperative parasternal long-axis view in patient 1. Notice the contribution of the secondary chordae of the MV in the LVOT obstruction. B, Postoperative parasternal long-axis view in late systole in patient 1. Notice the convex shape of the MV anterior leaflet, no SAM, and wide LVOT. MVAL, Mitral valve anterior leaflet; $M V P L$, mitral valve posterior leaflet; IVS, interventricular septum; $A 0$, aorta; $L A$, left atrium; $P M$, papillary muscles; $S C$, secondary chordae; $P C$, primary chordae; $P M$, papillary muscles; $C P$, mitral valve leaflet coaptation point.

TABLE 1. Baseline clinical characteristics of patients

\begin{tabular}{|c|c|c|c|c|c|c|c|c|c|c|c|c|}
\hline \multirow[b]{2}{*}{$\begin{array}{l}\text { Patient } \\
\text { No. }\end{array}$} & \multirow[b]{2}{*}{$\begin{array}{l}\text { Age } \\
\text { (y) }\end{array}$} & \multicolumn{2}{|c|}{ SAM } & \multicolumn{2}{|c|}{ LVOT $\Delta \mathbf{P}(\mathrm{mm} \mathrm{Hg})$} & \multicolumn{2}{|c|}{ MR } & \multicolumn{2}{|c|}{ Al } & \multicolumn{2}{|c|}{ TR } & \multirow[b]{2}{*}{$\begin{array}{c}\text { Follow-up } \\
\quad(\mathrm{mo})\end{array}$} \\
\hline & & $\begin{array}{c}\text { Pre-- } \\
\text { operative }\end{array}$ & $\begin{array}{c}\text { Post- } \\
\text { operative }\end{array}$ & $\begin{array}{c}\text { Pre- } \\
\text { operative }\end{array}$ & $\begin{array}{c}\text { Post- } \\
\text { operative }\end{array}$ & $\begin{array}{c}\text { Pre- } \\
\text { operative }\end{array}$ & $\begin{array}{c}\text { Post- } \\
\text { operative }\end{array}$ & $\begin{array}{c}\text { Pre- } \\
\text { operative }\end{array}$ & $\begin{array}{c}\text { Post- } \\
\text { operative }\end{array}$ & $\begin{array}{c}\text { Pre- } \\
\text { operative }\end{array}$ & $\begin{array}{c}\text { Post- } \\
\text { operative }\end{array}$ & \\
\hline 1 & 7 & Yes & No & 130 & 0 & I & I & I & I & 0 & 0 & 17 \\
\hline 2 & 8 & Yes & No & 105 & 30 & I & I & I & I & I & I & $*$ \\
\hline 3 & 5 & Yes & No & 150 & 15 & III & I & 0 & 0 & 0 & 0 & 1 \\
\hline
\end{tabular}

LVOT $\triangle P$, Left ventricular outflow tract gradient; $M R$, mitral regurgitation; $A l$, aortic insufficiency; $T R$, tricuspid regurgitation.

*No follow-up date.

degrees of LVOT obstruction. Multiple anatomic factors have been implicated in the LVOT. The hypertrophic septum; the abnormal alignment of the left ventricle, aorta, and MV axis; the malposed papillary muscles; and SAM of the MV have been suggested previously. ${ }^{4}$

On careful inspection of the MV motion on echocardiography, we noticed a significant contribution of the hypertrophied and shortened secondary chordae of the anterior mitral leaflet in the LVOT obstruction. The shortened secondary chordae had also deformed the anterior leaflet of the MV by pulling the midsegment of the leaflet toward the ventricle, thus preventing it from bellowing out toward the atrium. We also speculated the contribution of these chordae in causing SAM of the MV by pulling the coaptation plain of the valve closer to the septum.

In all 3 patients we performed radical excision of all of the secondary chordae of the anterior mitral leaflet. This helped eliminate part of the obstruction from the posterior aspect of the LVOT. Resection of the shortened secondary chordae liberated and moved the midsegment of the anterior leaflet of the MV away from the hypertrophied septum and probably contributed to the elimination of the SAM (Figure 1). We also performed posterior repositioning of both papillary muscles in patient 1 and one papillary muscle in patients 2 and 3 in an attempt to get the mitral subvalvular apparatus further away from the LVOT. In patient 1 we could see, through the aorta, that both commissural ends of the MV were involved in the SAM, whereas in patients 2 and 3 only the anterolateral commissural end was involved in the SAM, and hence only that papillary muscle was posteriorly repositioned. This judgment was made by inspecting the MV (through the aorta) for the presence of fibrosis and a thickening jet lesion of the subvalvular apparatus at each of the commissures.

In conclusion, we believe that in HOCM, secondary chordae of the anterior leaflet of the MV may become thickened and shortened as a result of turbulent flow in the LVOT, causing further obstruction of the latter. This thickening and shortening further crowd the LVOT and may contribute to the SAM. Resection of these chordae may be an important addition to our techniques in treating subaortic stenosis in cases of HOCM.

\section{References}

1. Morrow AG. Hypertrophic subaortic stenosis: operative methods utilized to relieve left ventricular outflow obstruction. $J$ Thorac Cardiovasc Surg. 1978;76:423-30.

2. Cooley DA, Leachmann RD, Hallman GL, Geramy S, Hall RJ. Idiopathic hypertrophic subaortic stenosis: surgical treatment including mitral valve replacement. Arch Surg. 1971;103:606-9.

3. Messmer BJ. Extended myectomy for hypertrophic obstructive cardiomyopathy. Ann Thorac Surg. 1994;58:575-7.

4. Levin RA, Vlahakes GJ, Lefebvre X, Guerrero JL, Cape EG, Yoganathan AP, et al. Papillary muscle displacement causes systolic anterior motion of mitral valve. Circulation. 1995;91:1189-95. 